\title{
Design, fabrication, and testing of SMA enabled adaptive chevrons for jet noise reduction
}

\author{
Travis L. Turner ${ }^{*}$, Ralph D. Buehrle ${ }^{* *}$, Roberto J. Cano ${ }^{\dagger}$, and Gary A. Fleming \\ NASA Langley Research Center, Hampton, VA USA 23681-2199
}

\begin{abstract}
This study presents the status and results from an effort to design, fabricate, and test an adaptive jet engine chevron concept based upon embedding shape memory alloy (SMA) actuators in a composite laminate, termed a SMA hybrid composite (SMAHC). The approach for fabricating the adaptive SMAHC chevrons involves embedding prestrained Nitinol actuators on one side of the mid-plane of the composite laminate such that thermal excitation generates a thermal moment and deflects the structure. A glass-epoxy pre-preg/Nitinol ribbon material system and a vacuum hot press consolidation approach are employed. A versatile test system for control and measurement of the chevron deflection performance is described. Projection moiré interferometry (PMI) is used for global deformation measurement and infrared (IR) thermography is used for 2-D temperature measurement and feedback control. A recently commercialized constitutive model for SMA and SMAHC materials is used in the finite element code ABAQUS to perform nonlinear static analysis of the chevron prototypes. Excellent agreement is achieved between the predicted and measured chevron deflection performance, thereby validating the design tool. Although the performance results presented in this paper fall short of the requirement, the concept is proven and an approach for achieving the performance objectives is evident.
\end{abstract}

Keywords: shape memory alloys, Nitinol, embedded actuators, jet engine chevrons, adaptive chevrons, shape control, deflection control, jet noise control

\section{INTRODUCTION}

Reduction of jet engine noise in the vicinity of airports continues to be of paramount importance. Recent research has shown that chevrons applied to the exhaust nozzle can reduce jet noise by as much as 2-3 EPNdB. Chevrons produce a "scalloped" trailing edge to the nozzle and protrude into the flow, increasingly from root to tip, in the flow direction. The noise reduction studies to date have been performed using static chevron technology, where the geometry and resulting flow immersion is predetermined and invariant. It has also been shown that the presence of the static chevrons induces a thrust loss of approximately $0.25 \%$. Thus, there exists a tradeoff between noise reduction at takeoff/landing and thrust reduction at cruise. The status of static chevron technology development can be reviewed in several recent studies $^{1-4}$.

One means of addressing the tradeoff of noise reduction and thrust penalty is the development of deployable (adaptive) chevrons. The adaptive chevron application appears to be ideal for shape memory alloy (SMA) actuation technology because SMA actuators can be thermally activated, they produce large force and stroke, and the quasi-static nature of adaptive chevron requirements alleviates issues associated with the limited frequency response of the thermoelastic shape memory effect. Shape memory alloys exhibit a phase transformation that is driven by temperature and stress. The thermally induced phase transformation is responsible for the well-known shape memory effect that is of primary interest in this study. Shape memory alloys can recover a large strain by this effect when heated in an unconstrained configuration and generate large forces when this recovery is constrained. Thus, the general concept for a SMA enabled adaptive chevron entails deploying the chevron under the actuation authority of prestrained SMA actuators. An example of a SMA-based adaptive chevron approach can be reviewed in a recent publication ${ }^{5}$.

\footnotetext{
* travis.1.turner@nasa.gov; phone 1757 864-3598; fax 1757 864-8823; Mail Stop 463; http://stab.larc.nasa.gov

ralph.d.buehrle@nasa.gov; phone 1757 864-7072; fax 1757 864-8823; Mail Stop 463; http://stab.larc.nasa.gov

† roberto.j.cano@nasa.gov; phone 1757 864-3951; fax 1757 864-8312; Mail Stop 226

* gary.a.fleming@nasa.gov; phone 1757 864-6664; fax 1757 864-8315; Mail Stop 493
} 
There are various ways that SMA actuators may be employed to enable deployable chevrons. Previous work at NASA Langley Research Center has demonstrated various structural control concepts via SMAHC laminates. In all cases, prestrained actuators were embedded in a composite during lamination and restrained during the elevated temperature cure. The adaptive chevron concept considered in this study consists of SMA actuators embedded on one side of the mid-plane of a laminated composite. Thus, thermal excitation causes the actuators to attempt recovery of the prestrain under the constraint of the bond to the host material. This asymmetry in thermal stress causes a moment that deflects the structure out of plane to the deployed state. The force developed in the host composite due to elastic strain during deployment is used to restore the structure to the stowed position.

Although autonomous chevrons are attractive and perhaps required for the most efficient operation in service, parametric studies in the laboratory are desirable to investigate effects such as variable immersion depth and circumferential distribution for optimal jet noise reduction. Thus, the present study will focus on chevron systems at model scale and provisions are made to electrically activate the SMA actuators to enable active control. The chevron concept described above lends itself to power-efficient electrical and/or autonomous environmental activation for versatility in parametric studies as well as in-flight optimization.

The objectives of this work are to develop a fabrication approach for SMAHC chevrons, develop numerical models of the chevron concept, design a prototype chevron with desired performance, perform bench top testing of the chevron specimens, and correlate measured performance with predictions. A thermoelastic model for SMA and SMAHC materials was recently implemented in the commercial codes MSC.Nastran and ABAQUS. Numerical results presented will be limited to those from ABAQUS. This study serves as the first use and validation of the model for shape control applications, so the parallel numerical and physical model development efforts will be described. Details of the fabrication processes, experimental arrangement, computational models, and correlation of bench top test and numerical results will be presented.

\section{SMAHC CHEVRON FABRICATION}

Pictures of the static chevron nozzle model that serves as motivation for the present work are shown in Figure 1 and Figure 2, without and with a pylon, respectively. The model is approximately $1 / 10^{\text {th }}$ scale with the bypass nozzle having 16 chevrons around the circumference and a radius of 4.865 inches $(12.357 \mathrm{~cm})$ at the root of the chevrons. Although the nozzle thickness is continuously tapered to the root of the chevrons, the chevron thickness is constant from root to tip. The static immersion of the chevrons is approximately 0.050 inches $(0.127 \mathrm{~cm})$ without flow loading effects. This geometry and configuration resulted from previous numerical and experimental work involving static chevron systems and represents a desirable configuration for an adaptive chevron approach. It is envisioned that adaptive chevrons would be retrofitted to a similar nozzle following detailed study of individual chevrons, which is the focus of this study.

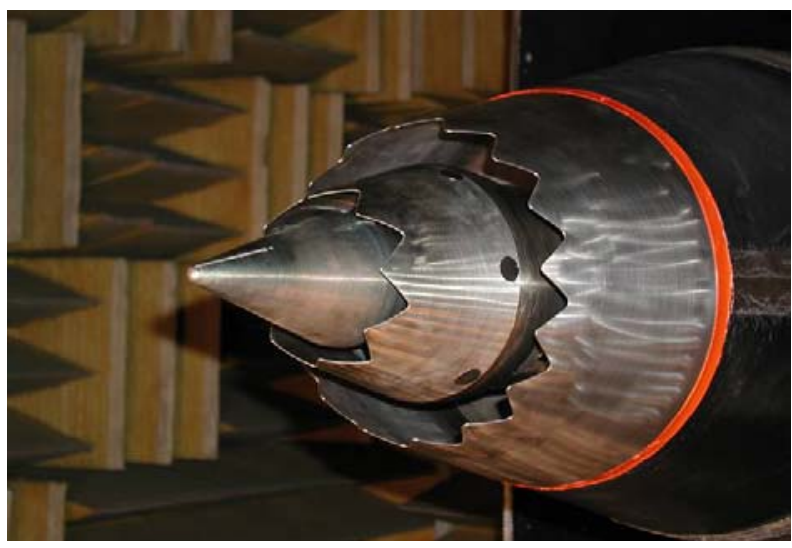

Figure 1: Static chevron scale nozzle model nozzle.

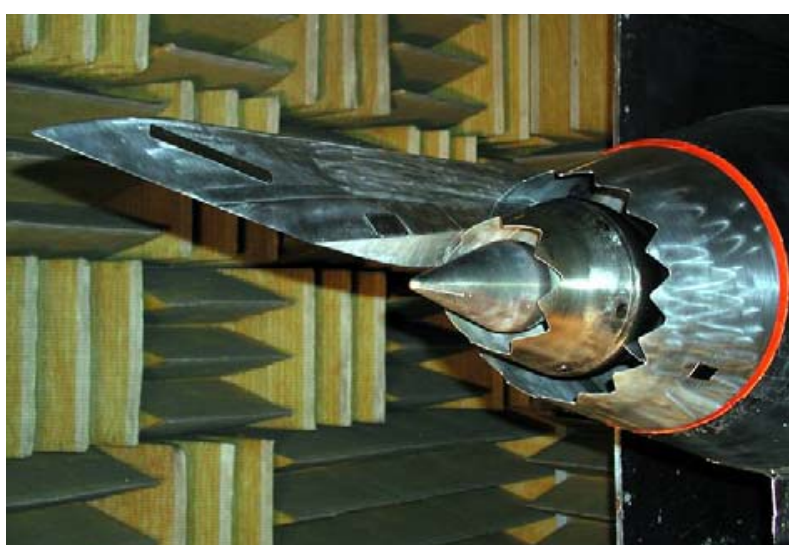

Figure 2: Static chevron scale nozzle model, with pylon.

A schematic of the SMAHC chevron planform geometry is shown in Figure 3. Consider a configuration with SMA actuator(s) embedded symmetrically about the planform centerline of the chevron. The schematic in Figure 4 represents 
a section through SMA actuators embedded along the centerline, which demonstrates the asymmetric actuator placement in the thickness direction to induce bending. The focus of this study is demonstration of the adaptive chevron concept, so all subsequent discussion of fabrication, testing, and numerical modeling will pertain to flat chevrons, i.e., without the cylindrical radius of curvature.

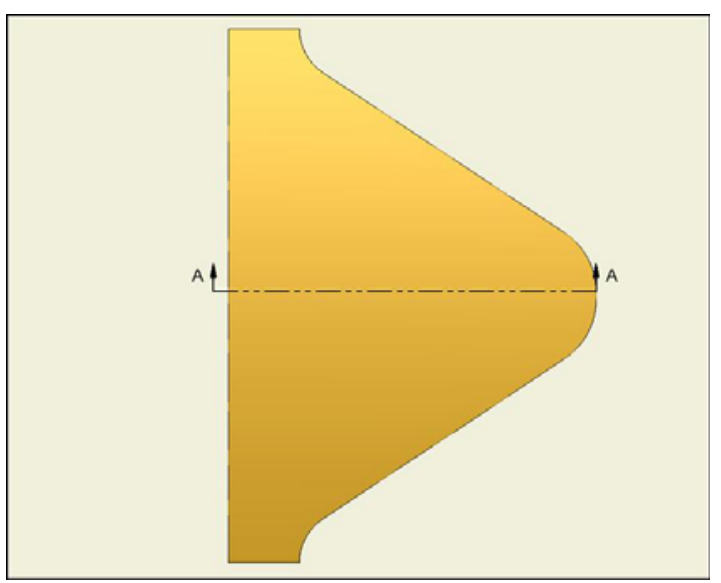

Figure 3: Planform view of adaptive chevron concept.

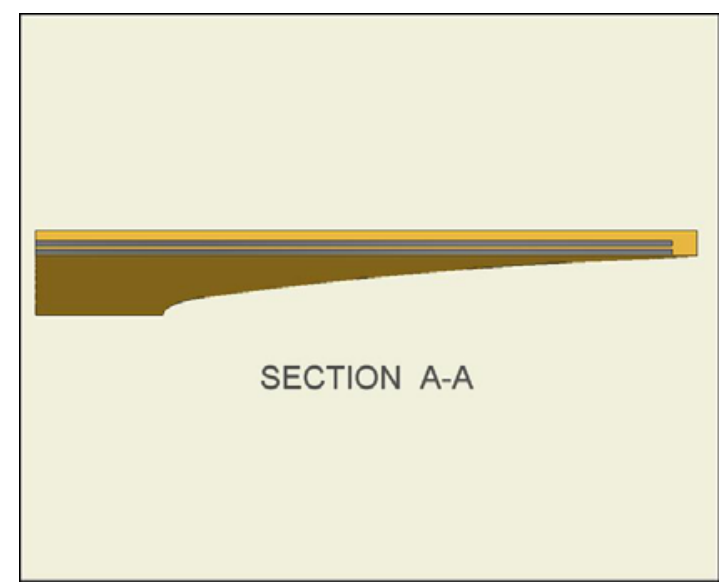

Figure 4: Cross section of adaptive chevron concept.

There are a several ways to approach fabrication of the laminated composite chevron. The process that was employed in the present study involved lamination of oversized layers, consolidation by vacuum hot press cure, and machining to final dimensions. Lamination of oversize layers was performed, in lieu of die-cut net-shape layers, to take advantage of existing molds and to allow for the most flexibility in planform geometry and lay-up/cure tooling. Vacuum hot press processing enabled rapid fabrication and high throughput, although this is offset somewhat in this case by the requirement for machining. This fabrication approach also simplified the actuator restraint mechanism, as compared to autoclave processing for example, which will be discussed in more detail below.

A SMAHC material system consisting of glass-epoxy unidirectional pre-impregnated (pre-preg) tape and Nitinol ribbon was selected for the present study. This material combination was selected because of several favorable properties and familiarity from previous experience. The glass-epoxy matrix material offers electrical isolation for resistive heating of the SMA actuators and affords visual flaw detection. Pre-preg material is available in thin layers and affords precise control over directional stiffness. A Nitinol alloy was selected due to its electrical resistance, shape memory capability, and availability. The ribbon (rectangular cross section wire) configuration simplified the fabrication procedure, by minimizing the number of actuators, and the mechanical/electrical connectivity of the structure in service. The glassepoxy material is an S2-glass/3501-6 material system with a nominal cured ply thickness of 0.004 inches $(0.01 \mathrm{~cm})$. The Nitinol ribbon was obtained with nominal cross section dimensions of $0.090 \times 0.006$ inches $(0.229 \times 0.015 \mathrm{~cm})$ and transformation temperatures, as determined by differential scanning calorimetry, of $\mathrm{A}_{\mathrm{s}}=113^{\circ} \mathrm{F}\left(45^{\circ} \mathrm{C}\right), \mathrm{A}_{\mathrm{f}}=140^{\circ} \mathrm{F}\left(60^{\circ} \mathrm{C}\right)$, $\mathrm{M}_{\mathrm{s}}=62.6^{\circ} \mathrm{F}\left(17^{\circ} \mathrm{C}\right)$, and $\mathrm{M}_{\mathrm{f}}=32^{\circ} \mathrm{F}\left(0^{\circ} \mathrm{C}\right)$.

There are several challenges posed by small thickness at model scale that greatly affect fabrication of the adaptive chevrons. The target overall thickness is 0.020 inches $(0.051 \mathrm{~cm})$, which severely limits the number of composite layers and actuator thickness. The requirements for electrical activation of the SMA actuators and for a clean trailing edge mandate electrical continuity of the actuator(s) within the chevron and two or more actuator ingress/egress points at the chevron root for electrical connectivity. The approach to satisfying these requirements involves doubling a prestrained Nitinol actuator back on itself, making a tight radius about a round wire loop. The assembly is then embedded within the laminate such that the Nitinol bend is positioned near the intended chevron tip location and the two lengths of SMA are separated by a layer of glass-epoxy pre-preg for electrical isolation and durability. The two layers of Nitinol in Figure 4 exemplify this approach, although electrical continuity and connectivity are not represented. Preliminary numerical results indicated that two layers of the Nitinol actuators described above, embedded along the chevron centerline as indicated in Figure 4, would be sufficient to generate the required tip deflection amplitude of 0.050 inches $(0.127 \mathrm{~cm})$. Discussion in this paper will focus on this configuration. 
Details of the Nitinol embedding approach are clearer in the following description of a representative fabrication process. Although several different laminates were fabricated, the results will focus on a 5-layer laminate and the fabrication process for the 5-layer laminate will be described for illustration. The Nitinol ribbon material was prestrained (elongated) $4 \%$ and lightly sandblasted for a mechanically enhanced bond prior to SMAHC fabrication. A mold with internal dimensions of $2 \times 2$ inches $(5.08 \times 5.08 \mathrm{~cm})$ was available and close to the intended dimensions of the scale model chevron. Plies of the glass-epoxy material were cut to the mold dimensions and the lamination of the 5-layer chevron was performed according to the following sequence: (45/-45/90/SMA/-45/SMA/45). The upper $-45^{\circ}$ layer was cut into 1.25 inch $(3.175 \mathrm{~cm})$ and 0.75 inch $(1.905 \mathrm{~cm})$ segments and the 0.75 inch $(1.905 \mathrm{~cm})$ segment was added to the $45 /-$ 45/90 lay-up at the outboard edge prior to installing the actuator assembly. Round wire with a diameter of 0.010 inches $(0.025 \mathrm{~cm})$ was used in the actuator assembly and the assembly was installed on the lay-up centerline with the Nitinol bend meeting the 0.75 inch $(1.905 \mathrm{~cm}),-45^{\circ}$ segment. A picture of the lay-up after placing the remaining 1.25 inch $(3.175 \mathrm{~cm})-45^{\circ}$ segment between the two layers of Nitinol is shown in Figure 5. Note that release paper was still attached to the $-45^{\circ}$ segments in the picture. The final $45^{\circ}$ ply was added to the lay-up and the assembly was installed in the mold as shown in Figure 6. The large mold depth is an artifact of its previous use and not necessary for the present fabrication process. A layer of Kapton film and bleeder cloth was placed beneath and on top of the laminate. The Nitinol actuators protrude through a slit in a resin dam on one side of the mold and the round wire protrudes from the other side. Gripping assemblies firmly restrain the Nitinol and round wire on either side of the mold as shown in Figure 7, where the plunger is also shown installed. The resin dam provides a reference edge for machining to final dimensions, which is shown schematically in Figure 8. The laminate was subjected to the cure cycle recommended by the pre-preg manufacturer.

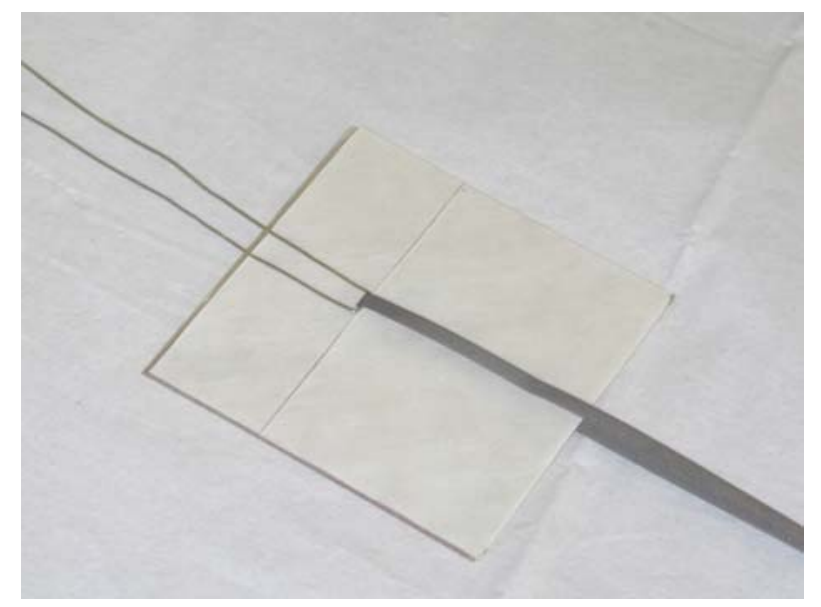

Figure 5: Placement of actuator assembly in laminate.

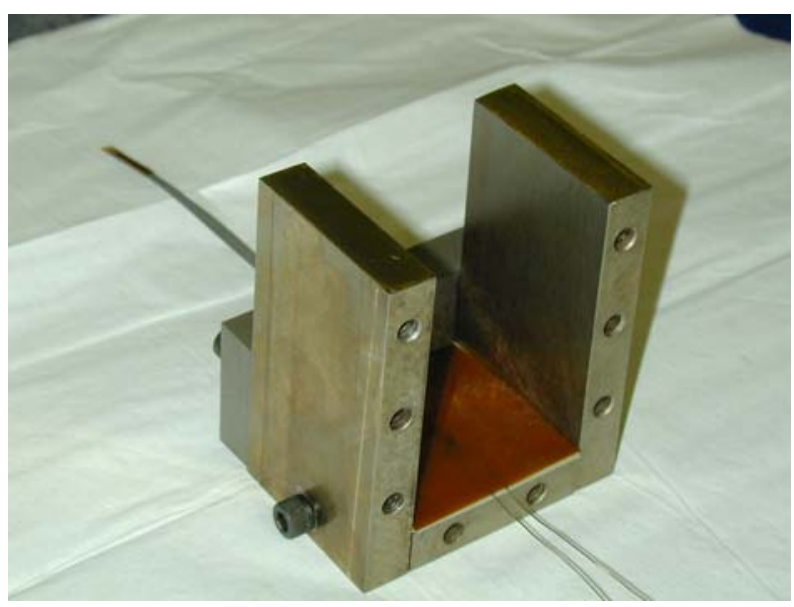

Figure 6: Finished chevron laminate installed in mold.

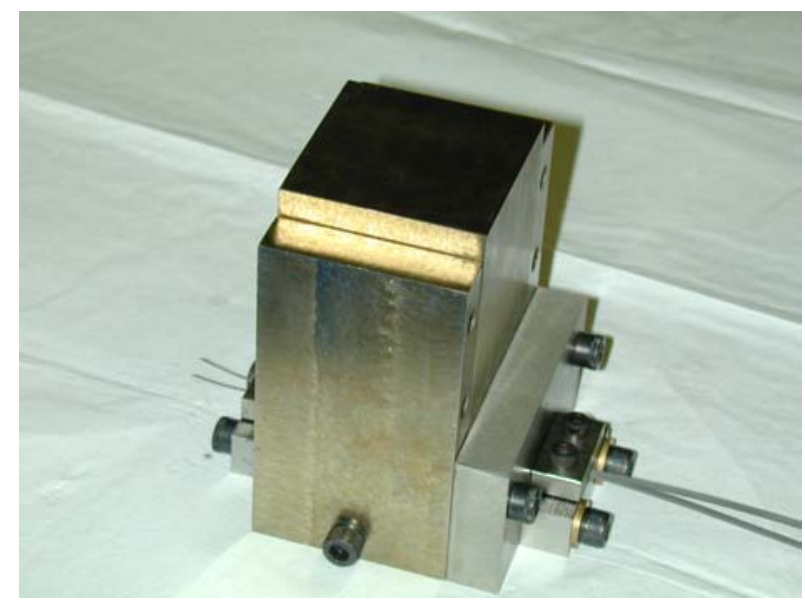

Figure 7: Fully assembled mold, ready for vacuum hot press.

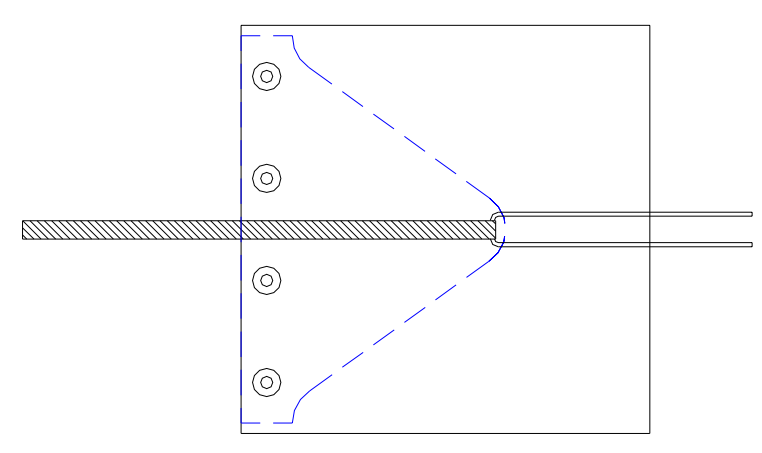

Figure 8: Schematic of machining to final dimensions. 
Some important notes on this fabrication approach are as follows. Although the laminate is asymmetric due to the embedded Nitinol ribbon, no warping of the laminate results after cure because the restraint on the actuators prevents recovery of the prestrain and participation in generation of a thermal moment during cooling. The consolidated laminate has a thickness of approximately 0.027 inches $(0.069 \mathrm{~cm})$ in the region away from the Nitinol and 0.029 inches $(0.074$ $\mathrm{cm}$ ) in the region with the Nitinol thickness contribution. It is apparent that there is significant compaction of the glassepoxy in the vicinity of the Nitinol inclusion due to the vacuum hot press processing approach. Conversely, the region away from the Nitinol exhibits a thickness greater than the nominal thickness suggested by the vendor. These observations held true for all chevron fabrication runs. It is clear that the round wire constraint is a critical element of this fabrication approach for two reasons; the Nitinol and round wire overlap region will be the thickest location in the part and the axial stiffness of the round wire restraint is less than optimal. The former issue results in the overlap region taking most of the load in the vacuum hot press, presenting the opportunity for fracture at the bend. It was anticipated, however, that the bearing load of the plunger during cure would help with the latter issue by constraining the actuator assembly.

\section{EXPERIMENTAL ARRANGEMENT}

An accurate and versatile test system was developed to rigorously measure and control the performance of prototype chevron specimens during development. The test system, shown in Figure 9, consisted of an optical bench for accurate component placement, a digital infrared (IR) camera for 2-D temperature measurement, a projection moiré interferometry (PMI) system for 2-D out-of-plane displacement measurement, a laser displacement transducer (LDT) for single point displacement measurement, and a LabVIEW-based test control and data acquisition system. The laser displacement transducer was a Keyence Model LK-081 and has the following specifications; measurement range 1.18 inches $(0.3 \mathrm{~cm})$ and resolution $(3 \mu \mathrm{m})$. The IR camera was a FLIR SC2000 that had an uncooled microbolometer focal plane array detector with an array size of $320 \times 240$ pixels. The accuracy of the IR camera was $\pm 2 \%$ and the digital resolution is 14-bit. The IR camera was used on a $32-932^{\circ} \mathrm{F}\left(0-500^{\circ} \mathrm{C}\right)$ range, which gives a temperature resolution of $0.05^{\circ} \mathrm{F}\left(0.03^{\circ} \mathrm{C}\right)$. The IR measurements were calibrated by adjusting the emissivity of the target so as to match the temperature of an attached thermocouple at elevated temperature.

A close-up view of a chevron specimen mounted to the support post is shown in Figure 10. The side of the chevron facing the IR and PMI systems was painted white to provide an opaque and diffuse scattering surface for the PMI system. Mechanical and electrical connections are made in the grip at the back edge of the mounting post. The grip consisted of a gripping bar embedded in a Garolite G10 (fiberglass) carrier. The G10 carrier provided the gripping pressure and electrically isolated the gripping bar from the support post. A layer of Kapton tape insulated the two Nitinol leads, starting at the edge of the chevron and ending at the back edge of the grip. Thus, the upper Nitinol lead made electrical connection to the gripping bar and the lower lead made connection to the support post. The remaining length of each lead was routed through a copper flashing and attached by a screw to the same respective electrical contacts. Direct electrical connectivity to power supply leads was accomplished in this manner.

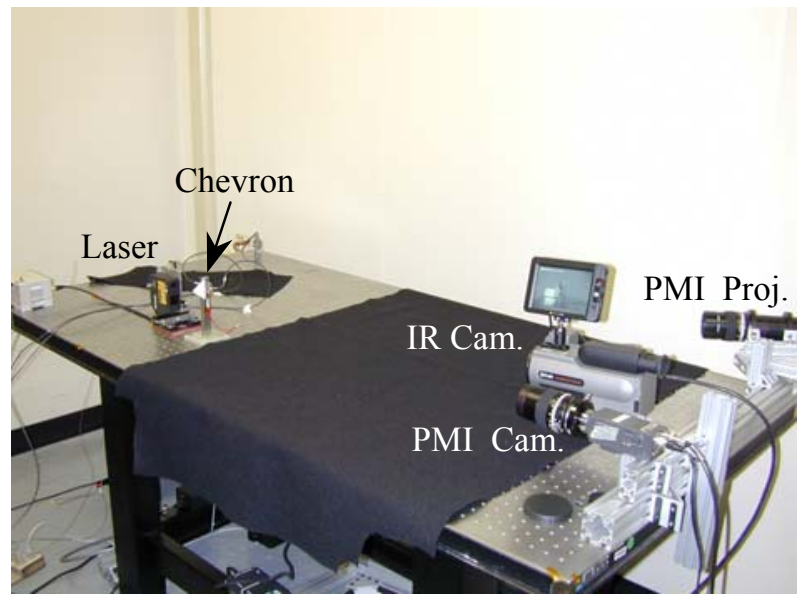

Figure 9: Overview of chevron test system.

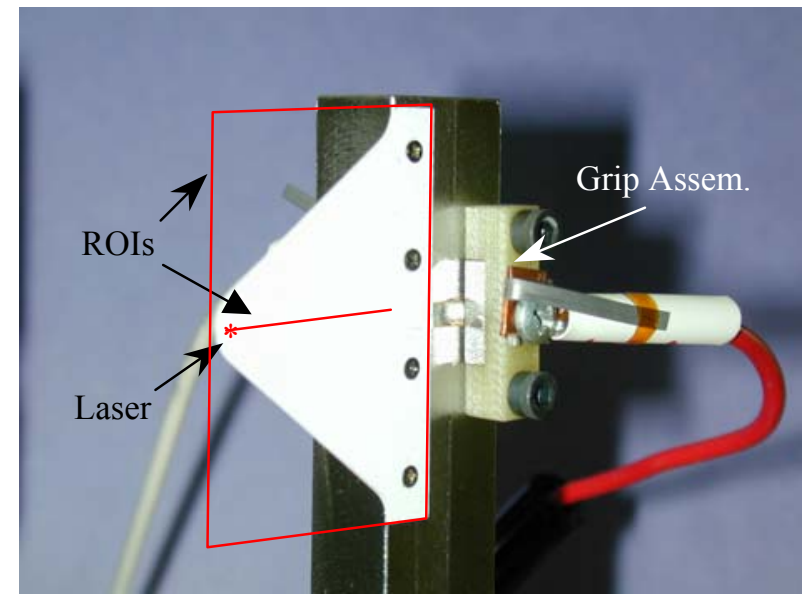

Figure 10: Close-up of chevron specimen mounted on post. 
The LabVIEW control and data acquisition system consisted of a PC configured with a National Instruments (NI) PCI1424 frame-grabber card, a NI PCI-6052E multifunction I/O card, and a NI PCI-GPIB card. The frame-grabber and RS232 connections established image acquisition and communication, respectively, with the IR camera. The multi-function I/O card, which was interfaced to a NI SC-2345 with SCC-series signal conditioning modules, performed the function of analog data acquisition from the laser displacement transducer and thermocouples. The multifunction I/O configuration was also used to provide a TTL trigger signal from the LabVIEW system to the PMI data acquisition system. Feedback control was achieved via a proportional-integral-derivative (PID) type controller with an average temperature from the infrared measurements as the control metric. Power was supplied to the chevron by a HP 6652A DC power supply operated in current control mode by direct GPIB commands from the LabVIEW system.

The PMI system was used to obtain global deformation measurements of the SMA-actuated chevron as a function of thermal load. The PMI technique is described in detail elsewhere ${ }^{6-8}$. The PMI video camera was a $1300 \times 1030$ pixel (width $\times$ height) camera equipped with a standard Nikon 105-mm lens. Video from the camera was digitized to 8-bits using a video frame grabber installed in a PC-compatible computer. The camera/lens combination yielded a $2.875 \times 2.250$ inch field-of-view (width $\times$ height) with a spatial resolution of $2.12 \mathrm{e}-3 \mathrm{inches} / \mathrm{pixel}(5.39 \mathrm{e}-3 \mathrm{~cm} / \mathrm{pixel})$. The PMI system projector was used to project a series of equispaced, parallel lines with a nominal grid line pitch of 0.026 inches $(0.066 \mathrm{~cm})$ onto the chevron surface as shown in Figure 11. Although the LDT was positioned on the opposite side of the chevron, a flare from the laser was visible to the camera, as shown in Figure 11. This flare corrupted the PMI data near the chevron tip. The PMI system was calibrated over a range that exceeded the anticipated range of chevron deformation and achieved a nominal random measurement error of \pm 0.0012 inches $( \pm 1 \sigma)$, uniformly distributed throughout the PMI system field-of-view. This random uncertainty was smaller than the estimated chevron surface roughness. In response to the TTL trigger signal, the PMI system acquired 10 images and averaged them for off-line processing. A representative deformation contour map from the PMI system is shown in Figure 12, where the tip of the deformation data has been cropped because of data corruption from the LDT flare.

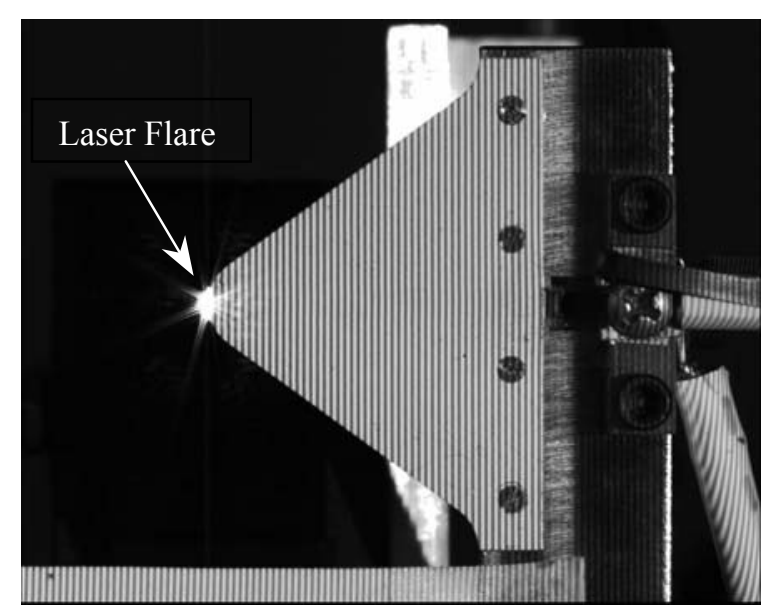

Figure 11: PMI grid lines projected onto chevron.

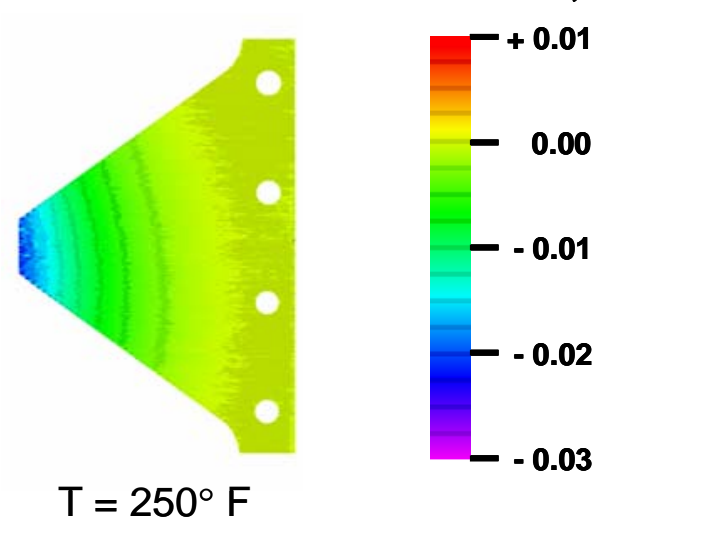

Figure 12: Typical PMI deformation contour map.

A typical test consisted of the following steps. The laser was positioned at a point on the chevron centerline and 0.055 inches $(0.140 \mathrm{~cm})$ from the tip. This location is indicated on the opposite side of the chevron in Figure 10 by the red asterisk and is close to the location of the first centerline node off the tip of the finite element model that will be discussed in the next section. Parameters were set in the LabVIEW data acquisition and control system to specify the setpoint distribution, trigger conditions, infrared regions of interest (ROI), control settings, etc. The typical setpoint distribution consisted of $10^{\circ} \mathrm{F}\left(5.6^{\circ} \mathrm{C}\right)$ increments from ambient temperature to $250^{\circ} \mathrm{F}\left(121.1^{\circ} \mathrm{C}\right)$ and back to ambient temperature. The typical ROI definitions were a rectangle encompassing the entire chevron and a line along the centerline of the Nitinol actuator from the tip of the chevron to the edge of the support post, as shown schematically in Figure 10. The average temperature of the line ROI was selected as the control metric for feedback. IR data was collected continuously for control purposes, but only recorded at the setpoints. The analog voltage and PMI data were also recorded at the setpoints, the latter coming as the result of the TTL trigger pulses. 


\section{NUMERICAL MODELING}

A thermoelastic model for SMA and SMAHC materials was recently implemented in the commercial finite element codes MSC.Nastran and ABAQUS. Numerical results will be limited to ABAQUS in the present study. Additional detail about the constitutive model and its implementation in the commercial codes can be found elsewhere ${ }^{9-10}$.

A finite element (FE) model of the adaptive SMAHC chevron was developed in MSC.Patran for pre-/post-processing. The chevron geometry was meshed using 700 quadrilateral (type S4) and 406 triangular (type S3) shell elements, as shown in Figure 13. Note that the mesh was constructed such that the width of the Nitinol ribbon constitutes four element widths along the chevron centerline. Thus, the elements in red are comprised of two layers of Nitinol in addition to the five layers of glass-epoxy (45/-45/90/SMA/-45/SMA/45) and the elements in blue have a lamination of glassepoxy layers only (45/-45/90/-45/45). The Nitinol layers in the SMAHC elements have an orientation angle of $0^{\circ}$. Recall that the glass-epoxy plies surrounding the Nitinol ribbon exhibit significant compaction during cure. The layer thickness distribution was modeled by dividing the measured thickness in the region away from the Nitinol evenly between the 5 glass-epoxy layers or 0.0054 inches $(0.0137 \mathrm{~cm})$ per layer. The thickness of the Nitinol layers was taken to be unchanged at 0.006 inches $(0.015 \mathrm{~cm})$ per layer and the balance of the thickness in the Nitinol region was distributed evenly amongst the 5 glass-epoxy layers or 0.0034 inch $(0.0086 \mathrm{~cm})$ per layer.

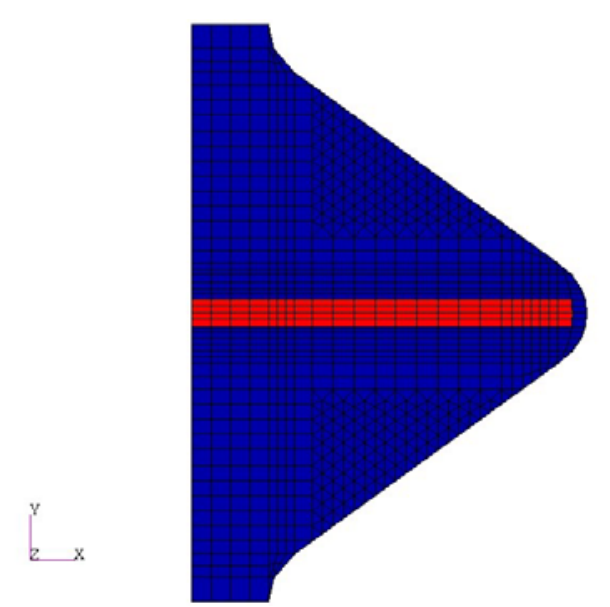

Figure 13: Geometry and FE mesh for SMAHC chevron.
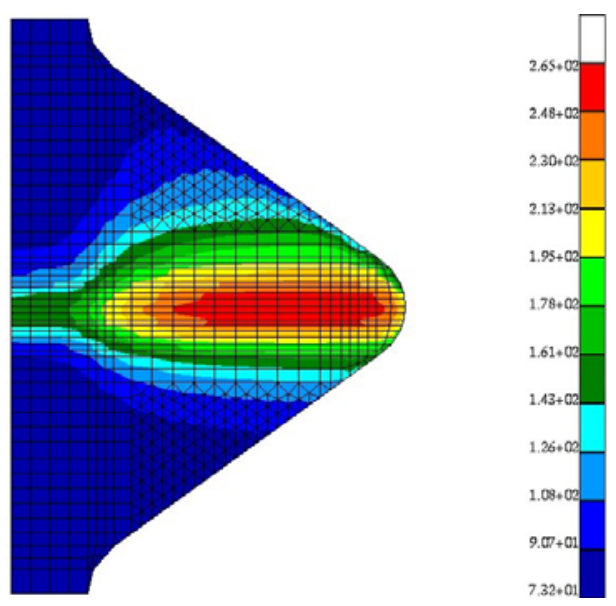

Figure 14: Measure temp. distr. interpolated onto FE mesh.

Thermomechanical characterization tests had been previously performed on the particular Nitinol ribbon material used in this study. However, properties specific to the glass-epoxy matrix material used in this study were not available, so approximate properties from a similar material system were used in the numerical predictions of the chevron performance. The temperature dependent orthotropic properties that were used in this study to model the Nitinol and glass-epoxy materials are shown in Table 1.

In an effort to model the constraint in the physical system, the three translation degrees of freedom (DOF) were constrained at the screw attachment nodal locations and the out-of-plane translation DOF were constrained over the entire mounting surface. In addition, all six DOF were constrained at the base of the Nitinol strips, where the chevron has mechanical and electrical connections. A uniform initial (ambient) temperature of $70^{\circ} \mathrm{F}\left(21.1^{\circ} \mathrm{C}\right)$ was applied to all of the nodes. The measured 2-D temperature distribution at the maximum temperature state in the experiment, control system setpoint of $250^{\circ} \mathrm{F}\left(121.1^{\circ} \mathrm{C}\right)$, was interpolated onto the finite element nodal locations, as shown in Figure 14, and applied as the thermal loading. Analysis input files for ABAQUS were generated from the finite element (FE) model in MSC.Patran. Nonlinear static analyses were performed with the 2-D temperature distribution defined by interpolation between the uniform ambient initial conditions and the final load temperature distribution to determine an approximate thermal load at each intermediate analysis increment. Tip deflections, centerline deflections, and deformation contours were generated for comparison with experimental results. 
Table 1: Orthotropic material properties for glass-epoxy and Nitinol.

\begin{tabular}{|c|c|c|c|c|c|c|c|c|c|c|c|c|}
\hline $\mathrm{T},{ }^{\circ} \mathrm{F}$ & $\alpha_{1}, /{ }^{\circ} \mathrm{F}$ & $\alpha_{2}, /{ }^{\circ} \mathrm{F}$ & $\mathrm{E}_{1}, \mathrm{psi}$ & $\mathrm{E}_{1}, \mathrm{psi}$ & $\mathrm{G}_{12}, \mathrm{psi}$ & $v$ & $\alpha_{1}, /{ }^{\circ} \mathrm{F}$ & $\alpha_{2}, /{ }^{\circ} \mathrm{F}$ & $\mathrm{E}_{1}, \mathrm{E}_{2}, \mathrm{psi}$ & $\mathrm{G}_{12}, \mathrm{psi}$ & $v$ \\
\hline \multicolumn{9}{|c|}{ Glass-Epoxy } \\
\hline 60 & $2.90 \mathrm{E}-06$ & $6.00 \mathrm{E}-06$ & $7.15 \mathrm{E}+06$ & $2.90 \mathrm{E}+06$ & $1.40 \mathrm{E}+06$ & 0.29 & $3.67 \mathrm{E}-06$ & $3.67 \mathrm{E}-06$ & $3.94 \mathrm{E}+06$ & $1.52 \mathrm{E}+06$ & 0.3 \\
\hline 80 & $3.07 \mathrm{E}-06$ & $6.84 \mathrm{E}-06$ & $7.15 \mathrm{E}+06$ & $2.90 \mathrm{E}+06$ & $1.40 \mathrm{E}+06$ & 0.29 & $-8.58 \mathrm{E}-06$ & $3.67 \mathrm{E}-06$ & $3.60 \mathrm{E}+06$ & $1.38 \mathrm{E}+06$ & 0.3 \\
\hline 100 & $3.39 \mathrm{E}-06$ & $8.73 \mathrm{E}-06$ & $7.13 \mathrm{E}+06$ & $2.82 \mathrm{E}+06$ & $1.34 \mathrm{E}+06$ & 0.29 & $-2.33 \mathrm{E}-05$ & $3.67 \mathrm{E}-06$ & $2.91 \mathrm{E}+06$ & $1.12 \mathrm{E}+06$ & 0.3 \\
\hline 120 & $3.61 \mathrm{E}-06$ & $1.03 \mathrm{E}-05$ & $7.11 \mathrm{E}+06$ & $2.75 \mathrm{E}+06$ & $1.29 \mathrm{E}+06$ & 0.29 & $-5.02 \mathrm{E}-05$ & $3.70 \mathrm{E}-06$ & $4.55 \mathrm{E}+06$ & $1.75 \mathrm{E}+06$ & 0.3 \\
\hline 140 & $3.71 \mathrm{E}-06$ & $1.12 \mathrm{E}-05$ & $7.08 \mathrm{E}+06$ & $2.68 \mathrm{E}+06$ & $1.24 \mathrm{E}+06$ & 0.29 & $-7.30 \mathrm{E}-05$ & $3.89 \mathrm{E}-06$ & $6.18 \mathrm{E}+06$ & $2.38 \mathrm{E}+06$ & 0.3 \\
\hline 160 & $3.72 \mathrm{E}-06$ & $1.17 \mathrm{E}-05$ & $7.07 \mathrm{E}+06$ & $2.58 \mathrm{E}+06$ & $1.20 \mathrm{E}+06$ & 0.29 & $-6.28 \mathrm{E}-05$ & $4.15 \mathrm{E}-06$ & $7.96 \mathrm{E}+06$ & $3.06 \mathrm{E}+06$ & 0.3 \\
\hline 180 & $3.70 \mathrm{E}-06$ & $1.19 \mathrm{E}-05$ & $7.06 \mathrm{E}+06$ & $2.47 \mathrm{E}+06$ & $1.15 \mathrm{E}+06$ & 0.29 & $-5.27 \mathrm{E}-05$ & $4.45 \mathrm{E}-06$ & $9.31 \mathrm{E}+06$ & $3.58 \mathrm{E}+06$ & 0.3 \\
\hline 200 & $3.67 \mathrm{E}-06$ & $1.20 \mathrm{E}-05$ & $7.05 \mathrm{E}+06$ & $2.35 \mathrm{E}+06$ & $1.10 \mathrm{E}+06$ & 0.29 & $-5.19 \mathrm{E}-05$ & $4.70 \mathrm{E}-06$ & $9.00 \mathrm{E}+06$ & $3.46 \mathrm{E}+06$ & 0.3 \\
\hline 220 & $3.65 \mathrm{E}-06$ & $1.20 \mathrm{E}-05$ & $7.05 \mathrm{E}+06$ & $2.22 \mathrm{E}+06$ & $9.80 \mathrm{E}+05$ & 0.29 & $-4.54 \mathrm{E}-05$ & $4.89 \mathrm{E}-06$ & $9.54 \mathrm{E}+06$ & $3.67 \mathrm{E}+06$ & 0.3 \\
\hline 240 & $3.65 \mathrm{E}-06$ & $1.21 \mathrm{E}-05$ & $7.04 \mathrm{E}+06$ & $2.09 \mathrm{E}+06$ & $8.70 \mathrm{E}+05$ & 0.29 & $-3.96 \mathrm{E}-05$ & $5.03 \mathrm{E}-06$ & $1.01 \mathrm{E}+07$ & $3.88 \mathrm{E}+06$ & 0.3 \\
\hline 260 & $3.67 \mathrm{E}-06$ & $1.22 \mathrm{E}-05$ & $7.05 \mathrm{E}+06$ & $1.95 \mathrm{E}+06$ & $7.50 \mathrm{E}+05$ & 0.29 & $-3.56 \mathrm{E}-05$ & $5.15 \mathrm{E}-06$ & $1.03 \mathrm{E}+07$ & $3.95 \mathrm{E}+06$ & 0.3 \\
\hline 280 & $3.71 \mathrm{E}-06$ & $1.23 \mathrm{E}-05$ & $7.06 \mathrm{E}+06$ & $1.80 \mathrm{E}+06$ & $6.20 \mathrm{E}+05$ & 0.29 & $-3.31 \mathrm{E}-05$ & $5.24 \mathrm{E}-06$ & $1.01 \mathrm{E}+07$ & $3.89 \mathrm{E}+06$ & 0.3 \\
\hline 300 & $3.75 \mathrm{E}-06$ & $1.25 \mathrm{E}-05$ & $7.08 \mathrm{E}+06$ & $1.65 \mathrm{E}+06$ & $5.00 \mathrm{E}+05$ & 0.29 & $-3.10 \mathrm{E}-05$ & $5.31 \mathrm{E}-06$ & $9.97 \mathrm{E}+06$ & $3.83 \mathrm{E}+06$ & 0.3 \\
\hline
\end{tabular}

\section{EXPERIMENTAL AND NUMERICAL RESULTS}

Chevrons of 4 different lamination schemes consisting of $8,6,5$, and 4 layers were fabricated, tested, and analyzed numerically in parallel efforts to simultaneously validate the numerical approach and design an adaptive chevron with the required performance characteristics. A terse summary of these configurations and the numerical and experimental results are shown in Table 2. The thickness entries result from measurements on the chevrons in areas away from and coinciding with the Nitinol inclusion, respectively. The glass-epoxy compaction issue discussed above is apparent in all of these measurements. Appropriate layer thicknesses were estimated and used in the numerical predictions as described above for the 5-layer case. It can be seen that the measured and predicted results are in good overall agreement; the trends are similar although not equivalent. The measured results clearly demonstrate an important consequence of the compaction. Although the 4-layer chevron is closest to meeting the thickness goal, the tendency for the vacuum hot press approach to drive the actuators lower in the stack during consolidation becomes critical in this case, where the lower actuator layer has become antagonistic. The predicted results show a similar behavior. Both sets of results indicate that the 5-layer chevron has the best combination of thickness and performance.

Table 2: Predicted and measured tip deflection results summary from 4 chevron types $\left({ }^{*}\right.$ estimated).

\begin{tabular}{|c|c|c|c|c|c|}
\hline$\#$ & \multirow{2}{*}{ Lamination Sequence } & \multicolumn{2}{|c|}{ Thickness, inches } & \multirow{2}{*}{$\begin{array}{l}\text { Pred. Defl., } \\
\text { inches }\end{array}$} & \multirow{2}{*}{$\begin{array}{l}\text { Meas. Defl., } \\
\text { inches }\end{array}$} \\
\hline Layers & & w/o SMA & w/ SMA & & \\
\hline 8 & $45 /-45 / 45 /-45 /-45 / \mathrm{SMA} / 45 /-45 / \mathrm{SMA} / 45$ & 0.045 & $0.047^{*}$ & -0.012 & -0.010 \\
\hline 6 & 45/-45/90/90/SMA/-45/SMA/45 & 0.030 & 0.032 & -0.023 & -0.017 \\
\hline 5 & 45/-45/90/SMA/-45/SMA/45 & 0.027 & 0.029 & -0.022 & -0.020 \\
\hline 4 & 45/-45/SMA/-45/SMA/45 & 0.022 & 0.024 & -0.021 & -0.014 \\
\hline
\end{tabular}

The results presented in Table 2 are improved over initial comparisons because of numerical model refinements. The temperature distribution during heating of the chevrons in the bench top tests was quite nonuniform, as shown previously in Figure 14. The actuation authority of the Nitinol is highly temperature dependent. The host material resin modulus is also a strong function of temperature. The compaction issue described previously is also a significant effect because of its influence on actuator placement and resulting authority and because the overall stiffness of the structure is proportional to thickness cubed. Early results did not take these effects into account, with drastic consequences. For example, prediction of the 5-layer chevron performance assuming a uniform temperature distribution of $250^{\circ} \mathrm{F}\left(121.1^{\circ} \mathrm{C}\right)$ and a uniform layer thickness of 0.005 inches $(0.013 \mathrm{~cm})$ resulted in a tip deflection of -0.042 inches $(0.107 \mathrm{~cm})$. Inclusion of the measured temperature distribution improved the tip deflection prediction to -0.029 inches $(0.074 \mathrm{~cm})$. Of course, inclusion of both effects results in the tip deflection of -0.022 inches $(0.056 \mathrm{~cm})$. The 2-D results from these 
two less refined models are shown in comparison to the corresponding refined model results in Figure 15 through Figure 17. It can be seen that the deflected shape has changed along with the amplitude, as indicated by the fringe patterns.

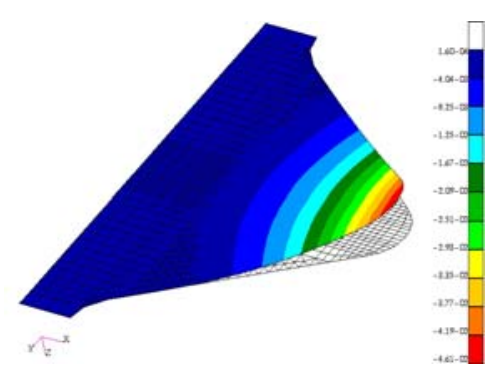

Figure 15: Uniform temperature and thickness.

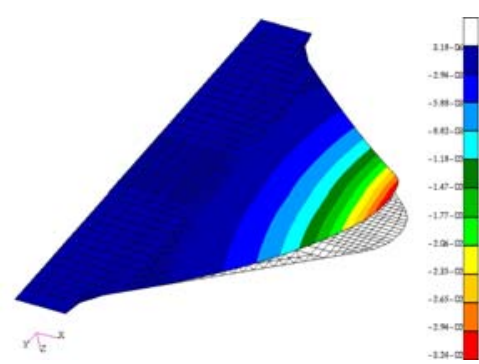

Figure 16: Measured temperature, uniform thickness.

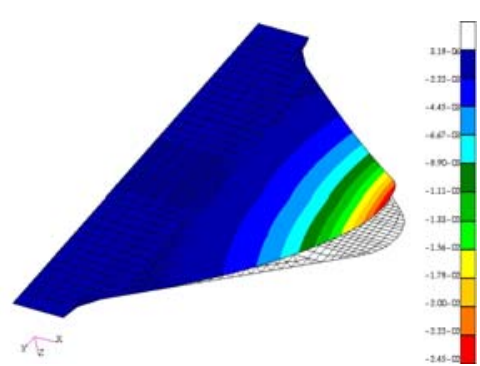

Figure 17: Measured temperature and non-uniform thickness.

The 5-layer chevron was subjected to a total of 53 thermal cycles according to the typical test procedure described in the Experimental Arrangement section. The Nitinol actuator was not "trained" prior to fabrication of the chevron, so changes in the actuation authority and hysteresis are expected. Some drift in the response is also expected as the actuator and host structure "settle in." The expected decrement in actuation authority and narrowing of the hysteresis loop are evident in Figure 18, which shows the tip displacement versus temperature as measured by the PMI system during the $1^{\text {st }}$ and $53^{\text {rd }}$ thermal cycles. The typical power consumption of the chevron in the course of these tests is 2.5 Watts ( 1 volt @ , $2.5 \mathrm{amps})$ at the peak setpoint temperature of $250^{\circ} \mathrm{F}\left(121.1^{\circ} \mathrm{C}\right)$. Note that the chevron has a significant nonzero deflection offset after the first thermal cycle. This offset was greatly reduced and was often nonexistent for the second and subsequent thermal cycles on every chevron tested, as indicated by the cycle 53 results in Figure 18.

Similar results comparing the tip deflection as measured by the laser displacement transducer and the PMI system and as predicted by the numerical model in ABAQUS are shown for thermal cycle number one in Figure 19. It can be seen that good qualitative agreement has been obtained between the prediction and measurements over the entire deflection range. The agreement between the prediction and PMI measurement is quantitatively good also. However, there appears to be an offset between the laser displacement transducer and PMI measurements. The laser displacement transducer results also show significant noise despite the fact that the instrument should have adequate resolution. It was determined subsequent to these tests that translucency of the resin in a composite material system produces spurious effects on laser displacement measurements. Thus, it is hypothesized that the discrepancies observed in this study may be attributable to this phenomenon as the back side of the chevron was not painted to render it opaque to the laser light.

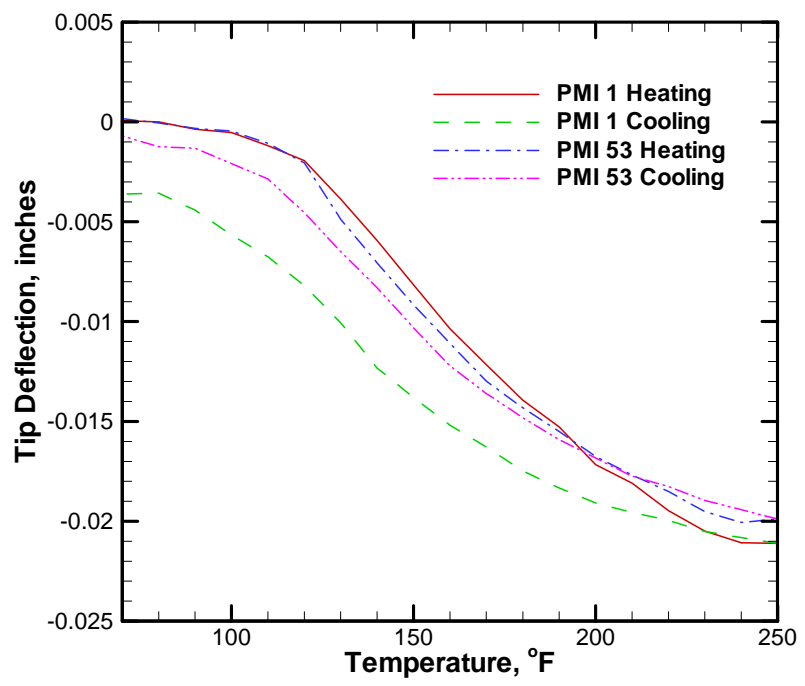

Figure 18: Tip deflection for thermal cycles 1 and 53 as measured by PMI.

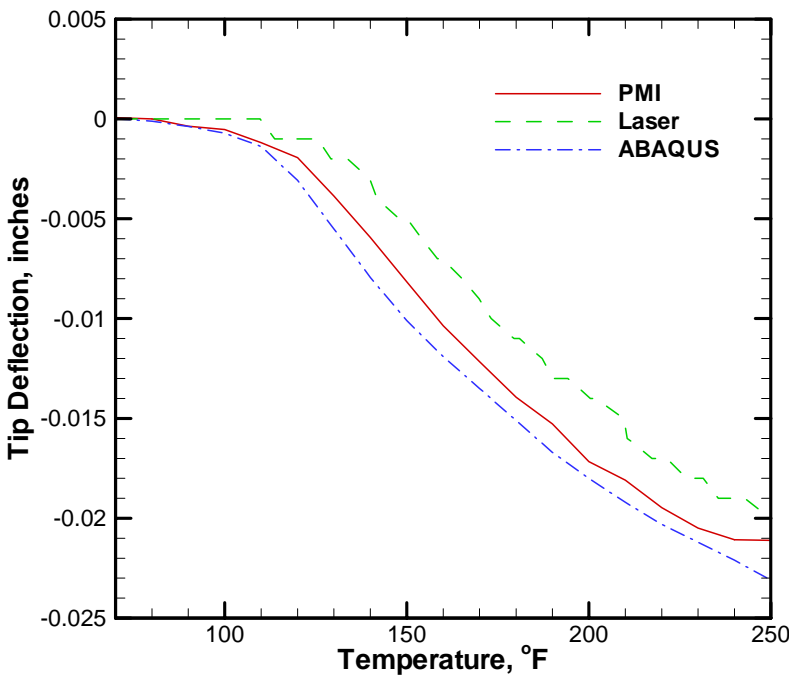

Figure 19: PMI, laser, and ABAQUS tip displacement versus temperature comparison. 
Some additional insight into the deformation comparisons between the FE model predictions and PMI measurements can be gleaned from the plot of centerline deflection shape versus temperature in Figure 20. The centerline shape is shown at ambient temperature and at three elevated temperatures; $130^{\circ} \mathrm{F}\left(54.4^{\circ} \mathrm{C}\right), 190^{\circ} \mathrm{F}\left(87.8^{\circ} \mathrm{C}\right)$, and $250^{\circ} \mathrm{F}\left(121.1^{\circ} \mathrm{C}\right)$. It can be seen that the predicted and measured results are in good agreement in both deflection amplitude and shape. Note that the PMI deflection data have been fit to remove variability due to surface roughness and to remove the corruption of the laser displacement transducer flare. The magnitude of these effects in the PMI measurements is shown in Figure 21 for the ambient temperature and $250^{\circ} \mathrm{F}\left(121.1^{\circ} \mathrm{C}\right)$ conditions.

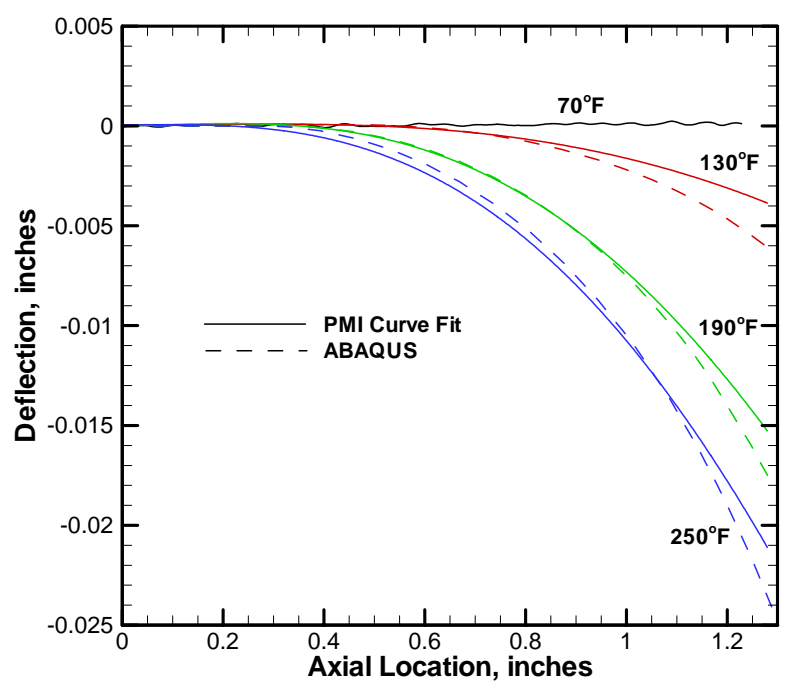

Figure 20: Centerline deflections at four temperatures.

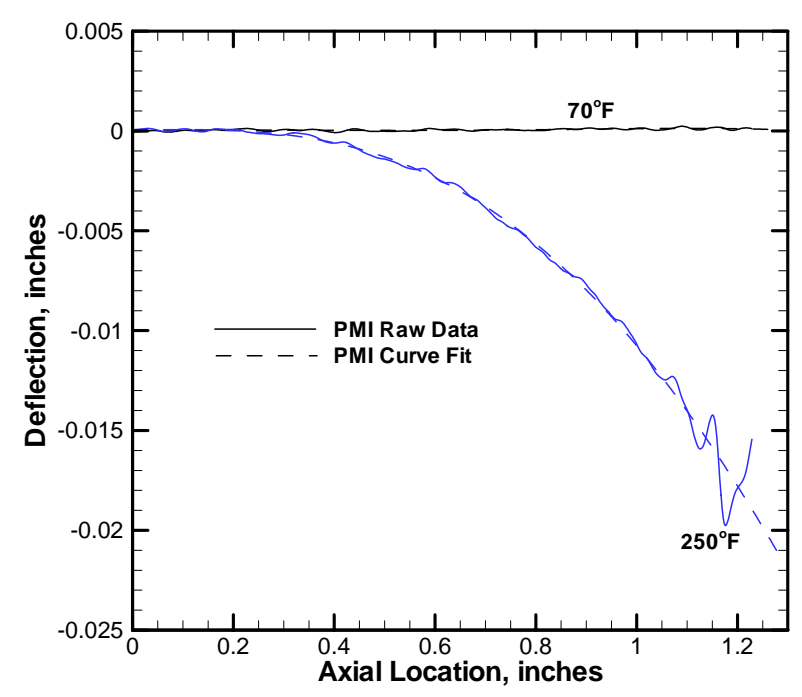

Figure 21: PMI centerline deflection raw data and curve fit.

A final comparison of the predicted and measured 2-D deflection field, at the fully deployed state with a thermal load corresponding to the $250^{\circ} \mathrm{F}\left(121.1^{\circ} \mathrm{C}\right)$ setpoint, is shown in Figure 22. The slight asymmetry is due to coupling stiffness of the laminate brought on by the asymmetric actuation. It can be seen that the agreement between prediction and measurement is excellent in both deflection amplitude and shape.
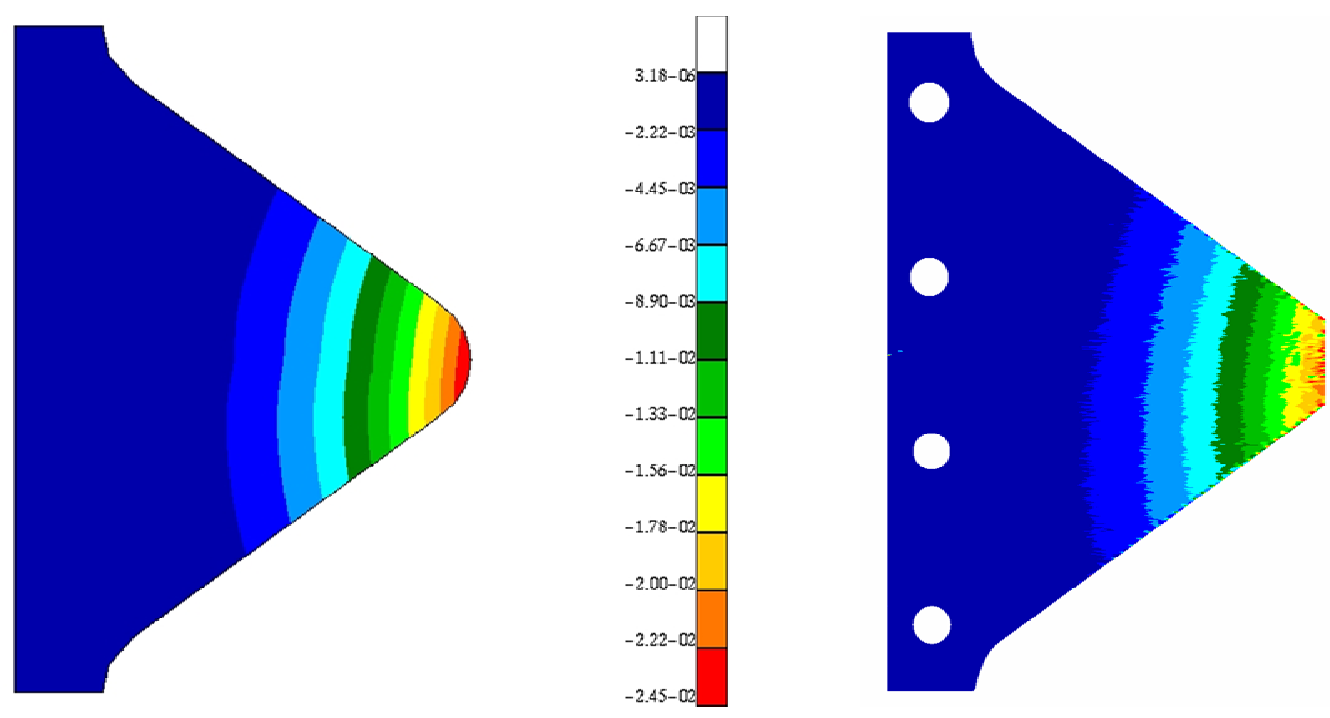

Figure 22: Predicted and measured 2-D deflection contours at the $250^{\circ} \mathrm{F}\left(121.1^{\circ} \mathrm{C}\right)$ setpoint.

Excellent agreement between the numerical model and measured performance of the SMAHC chevron concept has been demonstrated. However, the goal of 0.050 inches $(0.127 \mathrm{~cm})$ of tip displacement has not yet been achieved. The results presented above indicate that doubling the actuation authority may be sufficient to achieve the deflection goal. Work has 
been initiated in this direction and additional insight has been gained. Quantitative results are not available at this time, but some comments are warranted. Fabrication of a dual-actuator chevron according to the fabrication approach described above revealed a limitation. One of the two actuator assemblies and surrounding laminae will constitute the thickest location in the part. This location will take a majority of the load during cure and the other actuator assembly will be less constrained. An alternate actuator assembly approach is being pursued to alleviate these issues and will be the focus of the immediate future work on this topic.

\section{SUMMARY AND CONCLUSIONS}

A novel approach for adaptive jet nozzle chevrons has been developed based upon shape memory alloy hybrid composite (SMAHC) technology. The concept involves embedding prestrained SMA actuators on one side of the chevron midsurface in order to generate a thermal moment and deflect the structure out-of-plane when heated. The force developed in the host structure during deflection is used for returning the structure to the stowed position. The motivation for this work is to develop adaptive chevrons at model scale with provisions for electrical activation and active control to enable laboratory-based parametric studies, although the approach is thought to be applicable for autonomous environmental adaptation. The objectives of this study were to fabricate SMAHC chevrons at model scale, develop numerical models, and correlate predicted and measured performance to achieve a validated design tool and a prototype chevron design.

A fabrication approach was developed that involves lamination of glass-epoxy layers with two layers of embedded Nitinol ribbon between glass-epoxy layers and along the chevron centerline. A vacuum hot press consolidation approach was used for consolidation of the laminate. The actuator assembly was configured such that electrical continuity is maintained in the chevron with ingress/egress locations at the root. An integrated end constraint was developed for restraint of the Nitinol during elevated temperature cure. The thickness requirement of the model scale chevron proved to be a significant challenge in terms of number of plies, actuator assembly integration, etc. It was found that significant compaction of the glass-epoxy occurred in the region containing Nitinol because of the vacuum hot press consolidation. Chevrons with four lamination schemes were fabricated, consisting of 8, 6, 5, and 4 glass-epoxy layers, respectively.

A test system was developed to perform rigorous and comprehensive measurements of the SMAHC chevrons fabricated in this study. The system consisted of an infrared (IR) camera, a projection moiré inteferometry (PMI) system, a laser displacement transducer, and a LabVIEW-based test control and data acquisition system. The IR camera was used to capture 2-D temperature distributions and provide temperature data for feedback control. The PMI system measured the 2-D deflections of the chevron specimens and the laser displacement transducer provided redundant displacement measurement at a single point. The chevron was mounted in a cantilevered configuration and a mechanical grip provided actuator restraint and electrical connectivity for resistive heating. Thermal cycles were performed between the temperature of $70^{\circ} \mathrm{F}\left(21.1^{\circ} \mathrm{C}\right)$ and $250^{\circ}\left(121.1^{\circ} \mathrm{C}\right)$ while measuring the chevron temperature and deflection distributions.

A finite element model was constructed for the chevron geometry and input files were generated for nonlinear static analyses in ABAQUS according to a previously commercialized constitutive model for SMA and SMAHC materials. Preliminary numerical results indicated that a chevron concept with a single Nitinol actuator assembly would exhibit the desired performance. Modeling of the measured temperature distribution and glass-epoxy compaction proved to be critical in achieving good agreement between prediction and measurement. Refined numerical models that included these effects matched the experimental trends and excellent quantitative agreement was achieved between the predictions and measurements in both deflection amplitude and shape. The 5-layer chevron concept was found to provide the best performance and was close to the thickness goal. However, performance of the 5-layer chevron prototype did not meet the requirement. Work is continuing with the validated numerical analysis tool to design a chevron prototype with the required performance characteristics. Refinements in the fabrication approach are also underway.

\section{ACKNOWLEDGEMENTS}

The authors gratefully acknowledge Sean Britton (NASA LaRC) for his assistance in fabricating the chevron specimens. Thanks are also due to George Hilton (NASA LaRC) for his help in chevron fabrication and for his significant role in test system development and data collection. The authors also gratefully acknowledge Larry Becker and Brian Howerton (Lockheed Martin) for their work in developing the LabVIEW-based thermal controller/data acquisition system and Felecia Berry (NASA LaRC) for her assistance in configuring the PMI system. 


\section{REFERENCES}

1. O. Rask, E. Gutmark, and S. Martens, "Acoustic Investigation of a High Bypass Ratio Separate Flow Exhaust System", 42 ${ }^{\text {nd }}$ AIAA Aerosciences Meeting and Exhibit, AIAA Paper 2004-9, Reno, Nevada, 2004.

2. L. D. Koch, J. Bridges, and A. Khavaran, "Mean Flow and Noise Prediction for a Separate Flow Jet with Chevron Mixers", 42 ${ }^{\text {nd }}$ AIAA Aerosciences Meeting and Exhibit, AIAA Paper 2004-189, Reno, Nevada, 2004.

3. B. Callender, E. Gutmark, and S. Martens, "A PIV Flow Field Investigation of Chevron Nozzle Mechanism", $42^{\text {nd }}$ AIAA Aerosciences Meeting and Exhibit, AIAA Paper 2004-191, Reno, Nevada, 2004.

4. R. H. Thomas, K. W. Kinzie, and S. P. Pao, "Computational Analysis of a Pylon-Chevron Core Nozzle Interaction", $7^{\text {th }}$ AIAA/CEAS Aeroacoustics Conference, AIAA Paper 2001-2185, Maastricht, The Netherlands, 2001.

5. F. T. Calkins and G. W. Butler, "Subsonic Jet Noise Reduction Variable Geometry Chevron", $42^{\text {nd }}$ AIAA Aerosciences Meeting and Exhibit, AIAA Paper 2004-190, Reno, Nevada, 2004.

6. G. A. Fleming, "Surface Deformation Measurements", Optical Metrology for Fluids, Combustion, and Solids, Chapter 13, C. Mercer, Editor, Kluwer Academic Publishers, 2003.

7. G. A. Fleming, H. L. Soto, and B. W. South, "Projection Moire Interferometry for Rotorcraft Applications: Deformation Measurements of Active Twist Rotor Blades", American Helicopter Society 58th Annual Forum, Montreal, Canada, June 11-13, 2002.

8. L. Pirodda, "Shadow and projection moiré techniques for absolute or relative mapping of surface shapes", Optical Engineering, 21(4), 640-649, July/August 1982.

9. T. L. Turner, "A New Thermoelastic Model for Analysis of Shape Memory Alloy Hybrid Composites", Journal of Intelligent Material Systems and Structures, 11, 382-394, May 2000

10. T. L. Turner, "Analysis of SMAHC structures using commercial codes", in Smart Structures and Materials: Modeling, Signal Processing, and Control, R. C. Smith, Editor, Proceedings of SPIE Vol. 5383, Paper No. 12, 2004. 